\title{
DESENVOLVIMENTO DE BEBIDA ALCOÓLICA FERMENTADA OBTIDA A PARTIR DE RESÍDUOS AGROINDUSTRIAIS
}

\author{
L. I. F. PINTO ${ }^{1}$, M. M. N. ARAÚJO ${ }^{1}$, N. M. AMARAL 1 , S. C. P. MELO ${ }^{1}$, R. A. \\ ZAMBELLI $^{1}$ e D. F. PONTES ${ }^{1}$. \\ ${ }^{1}$ Universidade Federal do Ceará, Departamento de Tecnologia de Alimentos. \\ E-mail para contato: luanicaroxd@hotmail.com
}

\begin{abstract}
RESUMO - Este trabalho teve como objetivo o desenvolvimento de bebida alcoólica fermentada a partir de resíduos agroindustriais e avaliar suas características físicoquímicas. O resíduo de ameixa foi pasteurizado, tendo o seu teor de Sólidos Solúveis Totais corrigido com adição de sacarose e preparado o pé-de-cuba, logo após seguiu-se as etapas de filtração, fermentação, trasfega, envase, maturação, que ocorreu durante 15 dias à temperatura em torno de $10{ }^{\circ} \mathrm{C}$ para sedimentação das células de levedura; e armazenamento. $\mathrm{O}$ fermentado foi submetido às análises de acidez total, acidez fixa, volátil, densidade, $\mathrm{pH}$, teor alcoólico, extrato seco, minerais, açucares totais e redutores. Os valores encontrados foram: 46,10 $\pm 0,23 \mathrm{meq} / \mathrm{L}, 35,55 \pm 0,44 \mathrm{meq} / \mathrm{L}, 10,54 \pm 0,12$ meq/L, 0,9921, 3,55, 5,5\% (v/v), 20,1 g/L, 0,12\%, 4,44 g/100g e 1,36 g/100g, respectivamente. Pelo teor de açucares, o produto apresentou um caráter seco e apto para o consumo, além de ser uma nova forma de apresentação para o resíduo.
\end{abstract}

\subsection{INTRODUÇÃO}

Com crescimento do mercado de frutas e seus derivados têm ocorrido um aumento significativo na geração de resíduos nas agroindústrias. Os principais resíduos das indústrias processadoras de frutas são cascas, sementes, caroços e centro de frutas. Esses resíduos são constituídos de açúcar, fibras, vitaminas, sais minerais, podendo ser utilizado na alimentação humana e animal (Uchôa, 2007; Santana e Silva, 2008).

A utilização econômica de resíduos de frutas oriundos do mercado in natura ou das agroindústrias, aliada ao desenvolvimento de tecnologias para minimizar as perdas nos processos produtivos, podem contribuir de forma significativa para a economia do país e a diminuição dos impactos ambientais (Damiani et al., 2008).

Os resíduos de frutas podem ser aproveitados na formulação de vários produtos tais como geleias, barras de cereais, doces, fermentados, licores, biscoitos e chás (Uchôa, 2007).

De acordo com a legislação brasileira vigente, fermentado de fruta é a bebida com graduação alcoólica de quatro a quatorze por cento em volume, a vinte graus Celsius, obtida pela fermentação alcoólica do mosto de fruta sã, fresca e madura de uma única espécie, do 
respectivo suco integral ou concentrado, ou polpa, que poderá nesses casos, ser adicionado de água (Brasil, 2012).

A indústria alimentícia tem buscado novos tipos de bebidas, sabores, nichos de mercado, melhorando a sua qualidade e popularizando seu uso (De Marchi, 2006). Desta forma, o desenvolvimento de produtos é de vital importância para a sobrevivência e o crescimento do mercado de bebidas.

Diante dos exposto, o resíduo de Ameixa pode possuir uma importância socioeconômica, além de haver poucos relatos de aproveitamento deste resíduo, juntamente com a existência de crescimento na demanda de produtos à base de frutas típicas com características exóticas. Portanto objetivou-se nessa pesquisa elaborar uma bebida alcoólica fermentada a partir de resíduos agroindustriais de ameixa e avaliar suas características físicoquímicas.

\subsection{METODOLOGIA}

Os resíduos foram adquiridos por doação de Agroindústrias processadoras de frutas, localizadas na cidade de Fortaleza-CE, acondicionados em embalagem plástica e transportados em caixas isotérmicas para o Laboratório de Cereais, Departamento de Tecnologia em Alimentos da Universidade Federal do Ceará - UFC. Os demais ingredientes como a sacarose, a cultura starter (Saccharomyces cerevisiae) e a água mineral foram adquiridas no comércio varejista da cidade.

A formulação padrão foi estabelecida através de testes preliminares onde o ponto de equilíbrio entre os componentes e o parâmetro de graduação alcoólica foram levados em consideração para se chegar ao tratamento da Tabela 1.

Tabela 1 - Proporções das Matérias-primas utilizadas para fabricação do Fermentado de Ameixa

\begin{tabular}{cc}
\hline Matéria-prima & Quantidade \\
\hline Resíduo de Ameixa & $200 \mathrm{~g} / \mathrm{L}$ \\
Sólidos Solúveis Totais & $20^{\circ} \mathrm{Brix}$ \\
Saccharomyces cerevisiae & $2 \mathrm{~g} / \mathrm{L}$ \\
\hline
\end{tabular}

O fluxograma (Figura 1) apresenta as etapas do processamento do Fermentado de Resíduo de Ameixa: 


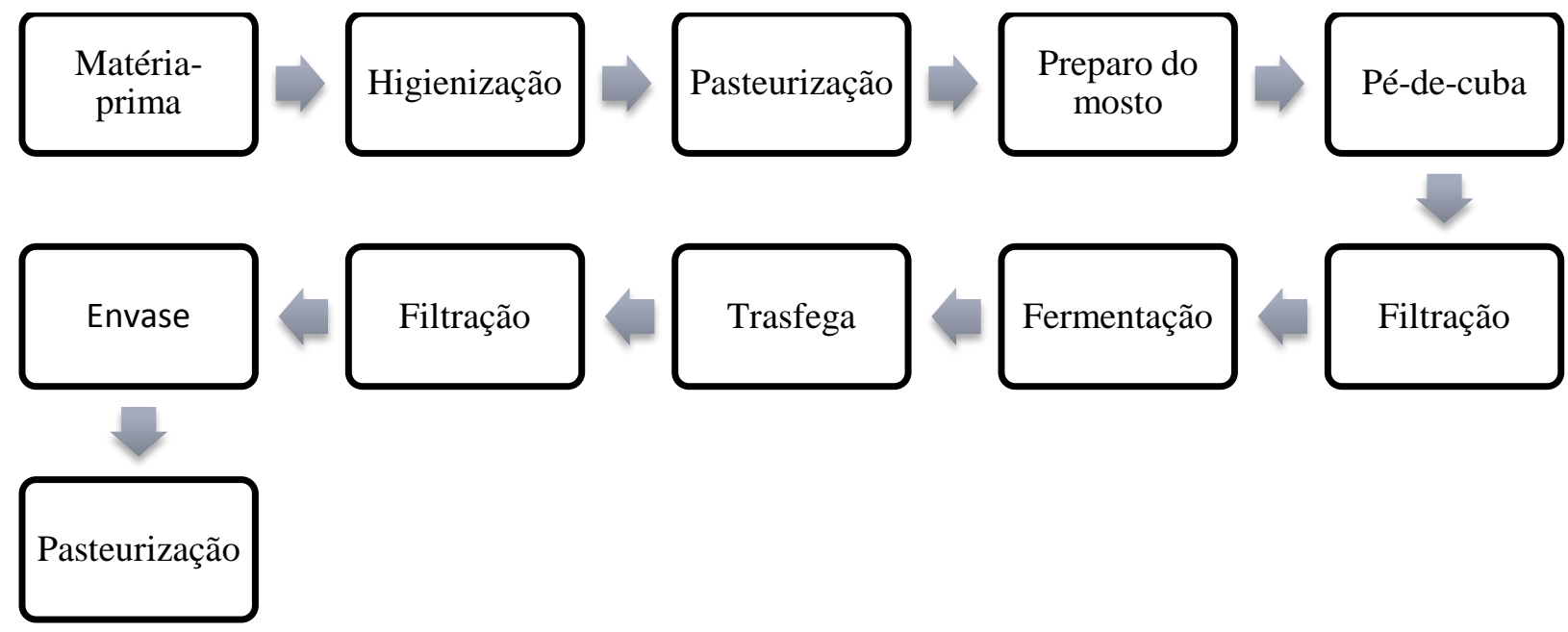

Figura 1 - Fluxograma do processamento do Fermentado

Conforme descrito na figura acima, higienizou-se o resíduo em água clorada a 100 ppm por $30 \mathrm{~min}$, logo após ocorreu uma separação, foi adicionado água mineral na proporção 5:1, ou seja, 1 litro de água para 200g de resíduo, corrigiu-se o pH com a adição de ácido cítrico $(1 \mathrm{~g} / \mathrm{L})$. Posteriormente, foi medido o teor de Sólidos Solúveis Totais ( ${ }^{\circ}$ Brix) e corrigido para se aferir conforme os valores apresentados na Tabela 1. Separou-se cerca de $20 \%$ do mosto onde foi adicionado a cultura (Saccharomyces cerevisiae, $2 \mathrm{~g} / \mathrm{L}$ ) e foi mantido em repouso por 24h, o restante do mosto foi colocado sobre refrigeração.

Decorrido às $24 \mathrm{~h}$, realizou-se a mistura do pé-de-cuba (mosto com cultura) ao restante do mosto, em seguida, o material foi colocado em um sistema de filtração tripla formada por películas de naylon e algodão a fim de reter a maior quantidade de impurezas. Logo após colocou-se a bebida em um sistema asséptico, para que ocorresse a fermentação. As trasfegas foram realizadas nos períodos de 7, 15 e 22 dias de fermentação.

Após esse período foi adicionado o metabissulfito de sódio $(0,2 \mathrm{~g} / \mathrm{L})$ para inibir o processo fermentativo e, em seguida, a bebida foi envasada em garrafas de vidro previamente esterilizadas, o produto foi pasteurizado a $60^{\circ} \mathrm{C} / 30 \mathrm{~min}$, rotulou-se e armazenado à temperatura ambiente, de $30^{\circ} \mathrm{C}$.

Para avaliar a estabilidade físico-química do fermentado foram realizadas analises no período de maturação, nos tempos 0, 30 e 60 dias após ser embalada. Os parâmetros utilizados foram: Acidez Total, Acidez Volátil, Acidez Fixa, Açúcares Totais, Açúcares Redutores, Cloretos Totais, Densidade, Extrato Seco, pH, Sólidos Solúveis Totais e Teor Alcoólico, conforme metodologia do Instituto Adolfo Lutz (2008).

A avaliação dos resultados dos parâmetros físico-químicos foram analisados através do teste de média e desvio padrão. A análise foi realizada no programa STATISTICA 7.0. 


\subsection{RESULTADOS E DISCUSSÃO}

A Tabela 2 apresenta os resultados para análises do Fermentado de resíduo de ameixa nos tempos 0,30 e 60 dias.

Tabela 2 - Estabilidade físico-química do fermentado de Resíduo de Ameixa

\begin{tabular}{|c|c|c|c|c|c|}
\hline Análises & \multicolumn{3}{|c|}{ Tempo } & \multicolumn{2}{|c|}{ Legislação* } \\
\hline $\begin{array}{l}\text { Acidez Total } \\
\quad(\mathrm{meq} / \mathrm{L})\end{array}$ & $\begin{array}{c}\mathbf{0} \\
46,10^{\mathrm{c}} \pm 0,32\end{array}$ & $\begin{array}{c}\mathbf{3 0} \\
56,21^{\mathrm{b}} \pm 0,52\end{array}$ & $\begin{array}{c}\mathbf{6 0} \\
61,03^{\mathrm{a}} \pm 0,12\end{array}$ & Mín. & $\begin{array}{l}\text { Máx. } \\
130\end{array}$ \\
\hline $\begin{array}{l}\text { Acidez Fixa } \\
(\text { meq } / \mathbf{L})\end{array}$ & $35,55^{\mathrm{c}} \pm 0,21$ & $43,28^{\mathrm{b}} \pm 0,01$ & $46,88^{\mathrm{a}} \pm 0,02$ & 30 & - \\
\hline $\begin{array}{l}\text { Acidez Vólatil } \\
(\mathrm{meq} / \mathrm{L})\end{array}$ & $10,54^{\mathrm{c}} \pm 0,23$ & $12,93^{b} \pm 0,23$ & $14,14^{\mathrm{a}} \pm 0,32$ & - & 20 \\
\hline $\begin{array}{c}\text { Açucares Totais } \\
(\mathrm{g} / \mathbf{1 0 0 g})\end{array}$ & $4,44^{\mathrm{a}} \pm 0,33$ & $3,31^{b} \pm 0,24$ & $3,03^{b} \pm 0,12$ & - & - \\
\hline $\begin{array}{c}\text { Açucares } \\
\text { Redutores }(\mathrm{g} / \mathbf{1 0 0 g})\end{array}$ & $1,36^{\mathrm{a}} \pm 0,45$ & $1,05^{\mathrm{a}} \pm 0,01$ & $0,876^{\mathrm{b}} \pm 0,04$ & - & - \\
\hline Densidade & $0,992^{\mathrm{a}} \pm 0,01$ & $0,992^{\mathrm{a}} \pm 0,02$ & $0,992^{\mathrm{a}} \pm 0,01$ & - & - \\
\hline Extrato Seco (g/L) & $20,05^{\mathrm{a}} \pm 0,05$ & $20,59^{\mathrm{a}} \pm 0,94$ & $20,83^{\mathrm{a}} \pm 0,72$ & 12 & - \\
\hline $\begin{array}{c}\text { Cloretos Totais } \\
(\%)\end{array}$ & $0,101^{\mathrm{c}} \pm 0,01$ & $0,137^{\mathrm{a}} \pm 0,07$ & $0,112^{b} \pm 0,01$ & - & 0,5 \\
\hline $\mathbf{p H}$ & $3,56^{\mathrm{a}} \pm 0,01$ & $3,58^{\mathrm{a}} \pm 0,01$ & $3,59^{\mathrm{a}} \pm 0,01$ & - & - \\
\hline $\begin{array}{c}\text { Sólidos Solúveis } \\
\text { Totais }\left({ }^{\circ} \text { Brix) }\right.\end{array}$ & $5,10^{\mathrm{a}} \pm 0,01$ & $4,90^{\mathrm{b}} \pm 0,01$ & $4,90^{\mathrm{b}} \pm 0,01$ & - & - \\
\hline $\begin{array}{l}\text { Teor Alcóolico } \\
\text { ( \% v/v) }\end{array}$ & $5,50^{\mathrm{a}} \pm 0,03$ & $5,30^{\mathrm{b}} \pm 0,01$ & $5,20^{c} \pm 0,02$ & 4 & 14 \\
\hline
\end{tabular}

Fonte: Pesquisa Direta *(BRASIL, 2012)

Os valores de acidez total obtidas diferiram de acordo com os tempos apenas depois de 30 trinta dias o Fermentado se apresentou de acordo com a da legislação vigente. Comparando com os fermentados de laranja (Mendes et al., 2001), Caju (FIlho et al., 2002), Abacaxi (Oliveira, 2012), Cajá (Dias, 2003), Fruto do Mandacaru (Oliveira, 2011) e Casca de Abacaxi (Silva, 2010) foi de 128,0 mEq/L, 118,0 mEq/L, 45,1 mEq/L, 29,0 mEq/L, 47,63 $\mathrm{mEq} / \mathrm{L}$ e $87,09 \mathrm{mEq} / \mathrm{L}$, respectivamente.

Mostram que todos o Fermentando de Resíduo estão dentro do padrão para fermentados de frutas e as variações desse parâmetro se deve a diversos ácidos orgânicos naturalmente presentes no fermentado e se dá pelo somatório destes ácidos, onde pode se 
utilizar para detectar alterações indesejadas devido a micro-organismos quando os valores forem muito discrepantes ao preconizado pela legislação (Vogt, 1972).

A acidez volátil é resultante a da subtração da acidez fixa da acidez total e o conhecimento dessa quantidade de ácidos é de vital importância, pois indica uma medida de deterioração microbiana, principalmente de microrganismos do gênero Acetobacter que pode transformar o vinho em vinagre (Vogt, 1972).

Os resultados obtidos nesta pesquisa foram maiores que os encontrados por Mendes (2001) 2,5 mEq/L em Fermentado de Laranja, Filho (2002) 1,0 mEq/L em Fermentado de Caju, Oliveira (2012) 4,03 mEq/L em Fermentado de Abacaxi e Dias (2003) com 5,5 mEq/L em Fermentado de Cajá, mas dentro do permitido pela legislação, ao qual permite um máximo de $20 \mathrm{mEq} / \mathrm{L}$ (Brasil, 2012).

A acidez fixa encontrada no fermentado tiveram um aumento considerável aumentando de 35,55 no tempo 0 para 46,88 no tempo 60 , sendo que esse parâmetro mede a quantidade de ácidos não voláteis encontradas no produto, entre eles se destacam os ácidos málico, tartárico, lático, cítrico, entre outros, que se destacam por conferir um $\mathrm{pH}$ ácido ao produto, garantindo uma barreira para a contaminação da microbiata indesejada (Amerine, 1976).

A densidade encontrada obteve valores muito próximos (Tabela 1) isso devido ao processo fermentativo bem conduzido, pois os açucares restantes no meio não foram suficientes para aumentar a densidade do fermentado. Vogt (1972) relata que a densidade dos vinhos variam de acordo com teor de açúcar e de álcool, onde quanto maior a graduação alcoólica menor será a densidade e quanto maior os teores de açucares maior será a densidade, consequentemente vinhos com teores maiores de açúcar e teores alcoólicos menores apresentaram uma densidade superior a 1.

Os sólidos solúveis totais encontrados no Fermentado apresentaram um decréscimo ao longo do tempo de armazenamento, esse comportamento já esperado pois ainda existe fermentação mesmo após a pasteurização. Segundo Amerine e Ough (1976) o conhecimento desse parâmetro indica a quantidade de açúcar e o termino da fermentação.

Os resultados encontrados para Açúcares, sendo eles Redutores e Totais ao se comparar com os valores obtidos com Oliveira (2012) que produziu um Fermentado de de Calda de Abacaxi com valores de AR, ANR e AT com 7,96\%, 0,23\% e 8,25\%, respectivamente, nota-se que os valores do Fermentado são abaixo do encontrados pelo autor, onde esses teores podem variar de acordo com a quantidade de açúcares presente no mosto, eficiência da fermentação, temperatura, concentração da cultura fermentativa, dentre outros (Aquarone, 2003; Rodrigues, 1996).

$\mathrm{O}$ pH obtido de acordo com o tempo, variando de 3,56 a 3,59, valores próximos foram encontrados nos de Cajá (Dias, 2003), o de Laranja (Mendes et al., 2001) e o de Caju (Filho et al., 2002) com valores de 2,6, 3,8 e 3,3 respectivamente, todos os valores encontrados estão abaixo da faixa de segurança para o crescimento de Clostridium Botullinium agente causador do Botulismo que é de 4,5.

$\mathrm{O}$ extrato seco obteve uma variação pouco significativa, sendo que parâmetro é apresentado como referência da quantidade de produtos não voláteis presente nos fermentados, ou seja, uma indicação do conteúdo de açúcar no mosto, portanto, quanto 
maior o teor de açúcar inicialmente no mosto, maior será o resíduo não alcoólico (Lima, 2001).

\subsection{CONCLUSÃO}

Foi possível elaborar fermentado de resíduo de ameixa com boas caracteristicas físicoquímicas, com um prazo de validadade de, no mínimo 60 dias. Pelo teor de açucares, o produto apresentou um caráter seco e é uma nova forma de apresentação para o resíduo, agregando valor e reduzindo o impacto ambiental.

\subsection{REFERENCIAS}

AMERINE, M. A.; OUGH, C. S. Analisis de vinos y mostos. Zaragoza: Acribia, 1976

ANDRADE, J. S.; PANTOJA, L.; MAEDA, R. N. Melhoria do rendimento e do processo de obtenção da bebida alcoólica de pupunha (Bactris gasipaes Kunth). Ciência e Tecnologia de Alimentos, v. 23, p. 34-38, 2003

BADOTTI, F.; DARIO, M. G.; ALVES-Jr, S. L.; CORDIOLI, M.; MILETTI, L. C.; ARAUJO, P. S.; STAMBUK, B. U. Switching the mode of sucrose utilization by Saccharomyces cerevisiae. Micr. Cell Fact, v. 7, n. 4, 2008.

BRASIL. Ministério da Agricultura, Pecuária e Abastecimento. Portaria $\mathrm{N}^{\circ}$ 34, de 29 de Novembro de 2012. Decreto ${ }^{\circ}$ 6.871, de 04 de junho de 2009. Regulamenta os padrões de identidade e qualidade para bebidas alcoólicas fermentadas: fermentado de fruta, hidromel, fermentado de cana, fermentado de fruta licoroso, fermentado de fruta composto e saquê. Diário Oficial da União. 2012.

DAMIANI, C. I.; BOAS, E. V. de B. V.; SOARES JUNIOR, M. S. et al. Análise física, sensorial e microbiológica de geléias de manga formuladas com diferentes níveis de cascas em substituição à polpa. Ciênc. Rural, v.38, n.5, p.1418-1423, 2008

DE MARCHI, R. Bebida de maracujá natural "light" pronta para beber: formulação, produção e estudo de vida-de-prateleira. Campinas, Faculdade de Engenharia de Alimentos da Universidade Estadual de Campinas. 2006. 206 f. (Tese, Doutorado em Alimentos e Nutrição)

DIAS, D. R.; SCHAWN, R. F.; LIMA, L. C. O. Metodologia para elaboração de fermentado de cajá (Spondias mombin L.). Ciência e Tecnologia de Alimentos, Campinas, v. 23 n. 3, p. 342, set./dez. 2003.

FILHO, V. E. M., et al. Produção, processamento e análise bromatológica do vinho obtido de caju (Anacardium occidentale L.) Cad. de Pesq., v. 13, n 1, p. 46-59, 2002.

FONTAN, R. C. I. Cinética Da Fermentação Alcoólica Na Elaboração De Vinho de Melancia. CEPPA, v. 29, n. 2, p. 203-210, jul./dez. 2011 
INSTITUTO ADOLFO LUTZ. Normas analíticas do IAL: Métodos químicos e físicos para análise de Alimentos. 3. ed: São Paulo, 2008.

MENDES, J. C. Vinho de laranja (Citrus sinensis): produção, processamento e controle de qualidade (organoléptico e bromatológico). Cad. de Pesq., v. 12, n. 1/2, p. 132-149, jan/dez. 2001.

OLIVEIRA, A. S.; SANTOS, D. C.; OLIVEIRA, E. N. A.; SILVA, F. L. H.; FLORENTINO, E. R. Produção de fermentado alcoólico do fruto de mandacaru sem espinhos (Cereus jamacaru). Rev. Bras. Prod. Agroind., v. 13 p 271-277, 2011.

OLIVEIRA, L. A.; LORDELO, F. S.; TAVARES, J. T. Q.; CAZETTA, M. L. Elaboração de bebida fermentada utilizando calda residual da desidratação osmótica de abacaxi. Rev. Bras. Tecnol. Agroind., v 06, p. 702-712, 2012.

RODRIGUES, M. L.; ANDRIETIA, M. G. S. Controle da fermentação alcoólica através de testes microbiológicos e bioquímicos. Faculdade de Engenharia de Alimentos/UNICAMP, 1995. 54p.

SANTANA, M. de F. S. de; SILVA, I. C. Elaboração de Biscoitos com Resíduo da Extração de Suco de Caju. Belém: EMBRAPA, 2008

UCHÔA, A. M. A. Adição de pós alimentícios obtidos de resíduos de frutas tropicais na formulação de biscoitos. 2007. 89f. Dissertação (Mestrado em Tecnologia de Alimentos) Universidade Federal do Ceará - UFC, Fortaleza, 2007.

VOGT, E. La fabricacion de vinos. Zaragoza: Acribia, 1972 